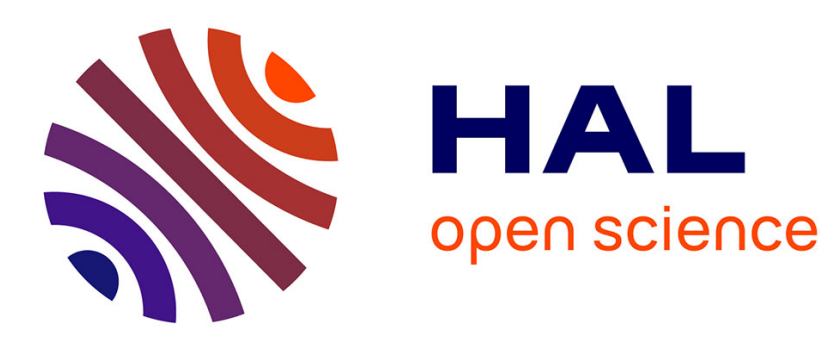

\title{
Texture Transformations in Thermomechanically Treated Steels Having Increased Nitrogen Content and Alloys
}

L. Kaputkina, G. Mavrich, V. Prokoshkina

\section{- To cite this version:}

L. Kaputkina, G. Mavrich, V. Prokoshkina. Texture Transformations in Thermomechanically Treated Steels Having Increased Nitrogen Content and Alloys. Journal de Physique IV Proceedings, 1995, 05 (C8), pp.C8-355-C8-360. 10.1051/jp4:1995852 . jpa-00254101

\section{HAL Id: jpa-00254101 https://hal.science/jpa-00254101}

Submitted on 1 Jan 1995

HAL is a multi-disciplinary open access archive for the deposit and dissemination of scientific research documents, whether they are published or not. The documents may come from teaching and research institutions in France or abroad, or from public or private research centers.
L'archive ouverte pluridisciplinaire HAL, est destinée au dépôt et à la diffusion de documents scientifiques de niveau recherche, publiés ou non, émanant des établissements d'enseignement et de recherche français ou étrangers, des laboratoires publics ou privés. 


\title{
Texture Transformations in Thermomechanically Treated Steels Having Increased Nitrogen Content and Alloys
}

\author{
L.M. Kaputkina, G.V. Mavrich and V.G. Prokoshkina \\ Moscow Steel and Alloys Institute, Leninsky prospect 4, Moscow 117936, Russia
}

\begin{abstract}
Ahstract. In this study the results of mathematical simulation and experimental research of texture transition in stress assisted shear phase transformations are discussed. The orientation distribution function (ODF) calculation model to the any type crystalline lattice symmetry materials has been suggested. By crystalline lattice symmetry analysis this computer program determines necessary amount of the initial experimental data. The experimental verification supports this model well. The ODF calculation model after shear phase transformation with equal use of all possible variants of orientation relationship or with various degrees of variant selection worked out. In this study the experimental and calculating data of the direct and reversal shear transformations $\alpha \Leftrightarrow \gamma$ in Fe-alloys and $\mathrm{B} 2 \Leftrightarrow \mathrm{B} 19^{\prime}$ in Ti-Ni alloys are discussed. The stress assisted shear phase transformation model and computer program to calculate ODF after transformation have been worked out.
\end{abstract}

\section{INTRODUCTION}

Metals and alloys with phase transformations in a solid state possess some important peculiarities of the crystallographic texture formation. The results of computer simulations and experimental study of texture transformations in $\mathrm{Ti}-\mathrm{Ni}$ alloys and steels, including steels with increased nitrogen content, during shear phase transformations under stress are discussed in present paper.

The nitrogen as alloying element is effective for the strengthening of $\mathrm{Cr}-\mathrm{Ni}$ and $\mathrm{Cr}-\mathrm{Mn}$ steels. At the same time introduction of the nitrogen in a steel, particularly high-strength steel, is accompanied by its brittleness due to nitride formation at grain boundaries. Therefore for high-nitrogen steels the thermomechanical treatment is perspective and processes of a texture formation are important. Moreover the nitrogen being an austeniteforming element lowers the temperatures of the martensitic transformation and changes the specific mechanism of the martensitic transformation due to lowering the stacking fault energy, i.e., causes increase in probability of transformation sequence. It can lead to some peculiarities of texture transformations and also can intensify a manifestation of the shape memory effect and of the hereditary influence of the initial texture.

\section{ODF CALCULATION PROCEDURE}

The mathematical model and ODF calculation computer program to the any type crystalline lattice symmetry materials by Roe approach[1] have been elaborated. 
In this model initial data to calculate ODF is pole figures (PF). The preliminary estimation procedure of the necessary PF amount depended on required accuracy of the ODF calculation has been worked out by crystalline lattice symmetry analysis[2].

The results of the ODF calculation are the library files concluded ODF and its coefficients calculated with required step on Euler angles $\phi, \theta, \psi$ with its translating into indexes of the crystalline plane and directions.

\subsection{ODF after shear phase transformation}

To calculate ODF after shear phase transformation without stress the model to materials with any type crystalline lattice symmetry has been developed.

ODF coefficients after shear phase transformation without any orientation relationship variant selection [3]are:

$$
\left.W_{1 \mathrm{mn}}=(2 /(21+1))\right)^{1 / 2} \sum_{i=-1}^{l} W_{1 \mathrm{mp}} \sum_{i=1}^{N}(1 / N) Z_{1 p n}(\cos \beta) e^{i p \alpha} e^{i n \gamma},
$$

where $\mathbf{N}$ - possible variants of orientation relationship.

The computer program based on this approach was carried out to calculate orientation relationship matrix on required variants and to calculate ODF after shear phase transformation without stress.

The method to define amount and variant indexes of required orientation relationship to any type crystalline lattice symmetry has been developed. It was based on generation of all possible orientation relationship variants and selection by size.

ODF calculation can occur with equal use of all possible variants of orientation relationship or with various degrees of variant selection:

$$
W_{1 m n}=(2 /(21+1))^{1 / 2} \sum_{p=-1}^{I} W_{1 m p} \sum_{i=1}^{N} G_{i} Z_{1 p n}(\cos \beta) e^{i p \alpha} e^{i n \gamma},
$$

where $G_{i}$ - relative frequency of $i$-th variant.

\subsection{ODF after stress-assisted shear phase transformation}

$G_{i}$ is a part of $i$-th orientation of initial phase transformed to $j$-th orientation of final phase. Then

$$
w\left(g_{i}\right)=\sum_{i}^{N} G_{i}^{j} w^{w}\left(g_{i}\right)
$$

where $\mathrm{N}$ - possible variants of direct transformation orientation relationship. 
$G_{i}$ depends on $i-$ th orientation of initial phase and $j$-th shear system. To the fixed $j$ :

$$
\begin{aligned}
& w\left(\xi^{\prime}, \psi^{\prime}, \phi^{\prime}\right)=\sum_{I} \sum_{i} \sum_{i}\left((2 /(21+1))^{1 / 2} \sum_{p=-1}^{l} w_{1 m p} \sum_{i=1}^{N} G_{i} Z_{1 p n}\left(\cos \beta_{i}\right) e^{i p \alpha_{i}} e^{i n \gamma_{i}}\right.
\end{aligned}
$$

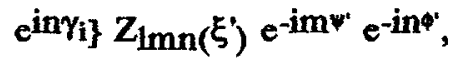

where $G_{i}=f\left(\xi^{\prime}, \psi^{\prime}, \phi^{\prime}, \alpha_{i}, \beta_{i}, \gamma_{i}\right)$, i.e. to the any orientation $g^{\prime}$ and $N$ orientation relationship variants $N$ varieties of $G_{i}$ occur.

Transformation probability on any orientation relationship variant is defined by relation of Shmid factors between this variant and all other.

Definition of Shmid factor to macrodeformation:

$$
\Theta(\overrightarrow{\mathrm{N}})=\cos (\hat{\mathrm{d}}, \hat{\mathrm{N}}) \cos (\overrightarrow{\mathrm{n}, \vec{N})},
$$

where $\overrightarrow{\mathbf{N}}$ - stress direction;

$\overrightarrow{\mathrm{n}}$ - normal to invariant plane;

$\overrightarrow{\mathrm{d}}$ - displacement vector.

Any ODF value of initial phase deals with crystalline plane and direction. If stress loads along only one direction in this crystallite crystalline direction concerned this ODF value is $\mathbf{N}$. It followed by that Shmid factor on fixed shear system depends on only stress direction, i.e. on crystalline direction corresponding ODF.That is why under uniaxial deformation all crystallites with equal crystalline direction corresponding ODF have equal Shmid factor.

The examination of the ODF model was carried out by comparing of orientations of texture maximums to the initial austenite pole figures for the steel 14Cr8NiMo2CuTi (with $0,06 \% \mathrm{C}$ ) after the hot rolling at $\mathrm{T}=950^{\circ} \mathrm{C}, \varepsilon=10 \%$. Calculations by $\mathrm{ODF}$ and direct pole figures give satisfactory coincidence: the principal texture components are $\{135\}<112\rangle$, $\{112\}<111\rangle$, the additional one is $\{011\}<211\rangle$. From the austenite ODF calculated using direct pole figure (the so-called "experimental") (Fig.1) the calculated martensite ODF was obtained using the model with equiprobable realization of the relationship variants. Comparison with direct pole figure and experimental martensite ODF shows that the model of texture transitions during martensitic transformations describes satisfactory these transformation in materials having weak texture. Applicability of the model to other shear transformations was studied during bainitic transformation in the $3 \mathrm{CrMoVSi}$ (with $0,6 \% \mathrm{C}$ ) steel in the course of low-temperature thermomechanical isothermal treatment $\left(\mathrm{T}=350^{\circ} \mathrm{C}\right.$, $\varepsilon=20+15 \%$ ). The principal austenite texture components are $\{h k 1\}\langle 111\rangle$, \{hk1\} $\langle 210\rangle$, the additional is $\{$ hkl $\}\langle 110\rangle$. Comparison of the ferrite ODF calculated using austenite ODF with the direct pole figure and experimental ODF shows that the calculated ODF is more sharp. It can be explained by the changes in orientations during transformation and in the stress state due to non-uniformity of deformation.

\section{RESULTS AND DISCUSSION}

For the study of texture transitions during the B19' $\rightarrow$ B2 transformation in Ti-Ni alloy the model of transformation under stress was used. The initial treatment was cold rolling by 
$\varepsilon=30 \%$. The specimens cut parallel to rolling direction, perpendicular to rolling direction and perpendicular to rolling plane were cyclically heated to $150,200,250$ and separately to $400^{\circ} \mathrm{C}$. The texture was obtained at room temperature for the B19' phase. The results of comparison of the B19' phase experimental ODF and of the calculated from B2 phase ODF for the transformation with equal use of all possible variants of orientation relationship and for the transformation under stress lead to the conclusion that the $B^{\prime} 19^{\prime} \Leftrightarrow$ B2 transformation is sensitive to the deformation orientation even after the unloading.

During the thermocycling in the course of B19' $\Leftrightarrow$ B2 transformations the crystallographic reorientation occurs. Therefore even for the transformations in a cycle "heating-cooling" it is impossible to use the model with equal use of all possible variants of orientation relationship. For the estimation of internal stresses (after deformation) and of transformation-induced hardening contributions to the crystallographic reorientation of the texture, the ODF was calculated for the cases of transformation under stress and of transformation with equal use of all possible variants of orientation relationship for specimens having different orientation to rolling plane and direction. For the $\mathrm{B}^{\prime} 9^{\prime} \Rightarrow$ B2 transformation the areas of orientations in Euler angles space taking part in transformation at uniaxial tension or compression were determined. The contribution of each orientation variant to the change of the shape anisotropy can be estimated.

The using of the transformation under stress model gives the better correspondence to experimental results and allows to explain the presence of a retained non-transformed phase (B19' for Ti-Ni alloy, retained austenite for the steel).

The $14 \mathrm{Cr} 8 \mathrm{Ni} 2 \mathrm{CuTi}$ (with $0,06 \% \mathrm{C}$ ) and $15 \mathrm{Cr} 5 \mathrm{Ni} 2 \mathrm{CuMoVN}$ (with $0,04 \% \mathrm{C}$ and 0,126 mass\% $\mathrm{N}$ ) were thermomechanically treated by HTMT (high temperature thermomechanical treatment) regimen ( $\mathrm{T}_{\mathrm{def}}=1050-950{ }^{\circ} \mathrm{C}, \varepsilon=80 \%$ ) providing maximum level of strength and plasticity. At room temperature the steels were in austenite state. The martensite was obtained by cold treatment at $-70{ }^{\circ} \mathrm{C}$. The texture was studied using specimens differently orientated to rolling plane and direction.

The texture of hot-deformed austenite is rather sharp and multicomponent. Texture maximums are described by $\{113\}\langle 110\rangle,\{130\}\langle 001\rangle,\{112\}\langle 312\rangle$ orientations. The texture of the austenite is non-nitrided steel is less sharp, probably due to partial recrystallization during hot deformation.

After cooling the texture of the martensite formed from hot-deformed austenite is less sharp. It is more scattered in nitrogen-containing steel. The texture of a retained austenite is much weaker than the texture non-transformed austenite and differs in principal orientations probably due to unequal probability of realization of different components and to deformation in the course of martensitic transformation.

The martensite texture in different steels includes the same and different orientations. Comparison of texture transitions of various texture components in both steels shows their different stability and different deformation in the course of transformation in steels investigated.

\section{CONCLUSIONS}

The method of calculation of textures and texture transitions in steels and alloys during shear phase transformations, including transformations under stress, is elaborated.

Texture and texture transitions in steels of near content and Ms temperatures with different nitrogen content after HTMT differ due to differences in texture of the initial austenite and to differences in the course of martensitic transformation. 

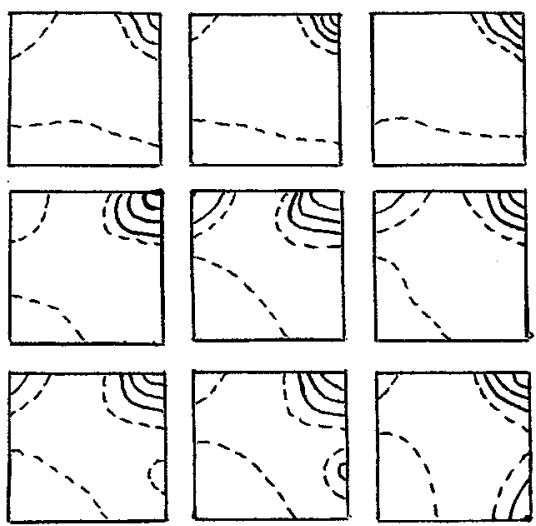

a

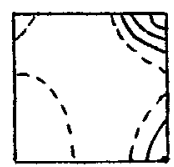

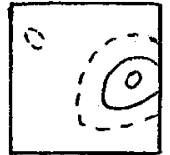
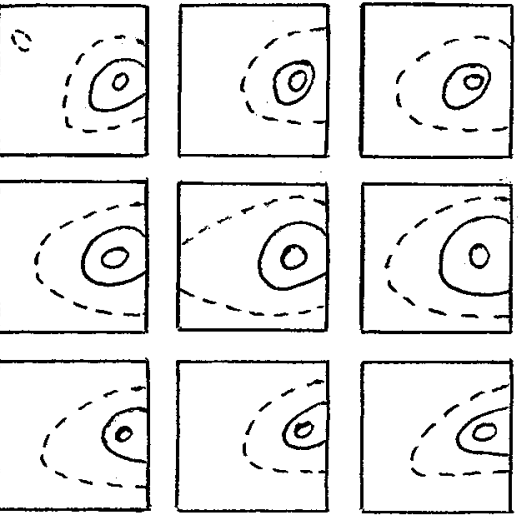

b
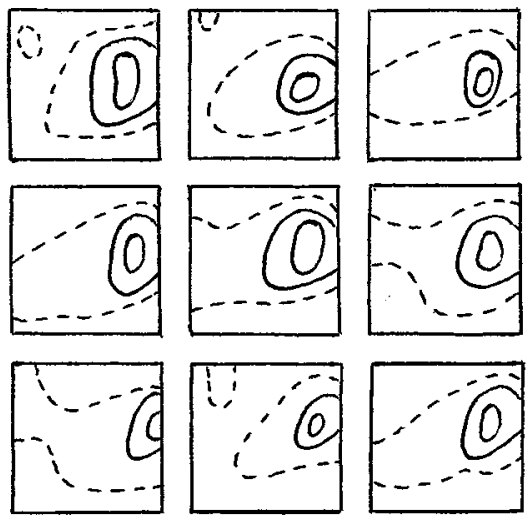

c

Figure 1: ODF for (a) experimental texture of austenite after hot rolling, (b) calculated texture of martensite, (c) experimental texture of martensite. $\phi=0^{\circ}-90^{\circ}, \Delta \phi=11.25^{\circ}$. Contour intervals $1.5 x r a n d o m$. 


\section{References}

(Periodicals)

[1] Roe R.J., J.Appl. Phys. 36 (1965) 2024-2031.

(Conference Proceedings)

[2] Mavrich G.V., "The algorithm and program to calculate texture transition during crystallographically odered phase transformation", 6th All Union Conference on Texture and Recrystallization of Metalls and Alloys, Sverdlovsk 11-15 March 1991, "UTAN" Association, 1991) pp.210.

(Conference Proceedings)

[3] Davies G.J. and Bateman R.M., "The influence of variavt selection in the inheritance of texture during phase transformations",6th International Conference on Texture of Materials, Tokyo 28 September-3 October 1981, pp 132-148. 